\title{
Laparoscopic Resection of a Giant Dedifferentiated Primary Retroperitoneal Mucinous Cystadenoma (PRMC) in a Young Woman: A Case Report and Literature Review
}

\author{
Liusheng $\mathrm{Wu}^{1,2}$, Xiaoqiang $\mathrm{Li}^{1,2 *}$, Jian $\mathrm{Li}^{3}$, and Yanwei Lai ${ }^{4 *}$ \\ ${ }^{1}$ Peking University Shenzhen Hospital, Clinical College of Anhui Medical University, Shenzhen, Guangdong, 518036, China \\ ${ }^{2}$ Department of Thoracic surgery, Peking University Shenzhen Hospital, Shenzhen, Guangdong, 518036, China \\ ${ }^{3}$ Department of Pathology, Peking University Shenzhen Hospital, Shenzhen, Guangdong, 518036, China \\ ${ }^{4}$ Department of Pharmacy, Peking University Shenzhen Hospital, Shenzhen, Guangdong, 518036, China
}

*Corresponding authors: Yanwei Lai, PhD, Professor, Department of Pharmacy, Peking University Shenzhen Hospital, Shenzhen, Guangdong, 518036, China, E-mail: 505272751@qq.com

Xiaoqiang Li, PhD, Professor, Department of Thoracic surgery, Peking University Shenzhen Hospital, Shenzhen, Guangdong, 518036, China, E-mail: dr.lixiaoqiang@gmail.com

Received: 01 Feb, 2021 | Accepted: 09 Feb, 2021 | Published: 16 Feb, 2021

Citation: Wu L, Li X, Li J, Lai Y (2021) Laparoscopic Resection of a Giant Dedifferentiated Primary Retroperitoneal Mucinous Cystadenoma (PRMC) in a Young Woman: A Case Report and Literature Review. J Clin Case Stu 6(1): dx.doi.org/10.16966/2471-4925.215

Copyright: (C) $2021 \mathrm{Wu} \mathrm{L}$, et al. This is an open-access article distributed under the terms of the Creative Commons Attribution License, which permits unrestricted use, distribution, and reproduction in any medium, provided the original author and source are credited.

\section{Abstract}

Background: PRMC is a very rare benign tumor of the abdominal cavity that usually occurs in women, and PRMC demonstrate no specific findings on CT. There are many reports on the differential diagnosis and discussion of PRMC imaging, but there are few reports on the treatment of dedifferentiated PRMC using laparoscopic resection and postoperative follow-up.

Case summary: A mass was discovered in the left abdomen of a 24-year-old woman during a physical examination 6 years ago, and she suddenly developed paroxysmal pain in her left middle abdomen 4 months prior. The imaging examination revealed that a large cystic lesion on the left abdomen and part of the small intestine had a slight dilation of the liquid-gas plane in the left middle and lower abdomen. Besides, she also had incomplete obstruction of the small intestine, and it was not clear whether this was caused by the mass in the left abdomen. Following multidisciplinary team discussion, we finally decided to perform laparoscopic exploration and those of cancer antigen (CA) 19-9 and 125 (CA125) were elevated. Pathological examination results: dedifferentiated PRMC.

Conclusion: Laparoscopy can effectively treat giant retroperitoneal mucinous cystadenoma with obvious therapeutic effects, and there is no tumor recurrence.

Keywords: Primary retroperitoneal mucinous cystadenoma (PRMC); Laparoscopic surgery; Large adenomas; Retroperitoneal tumor; Case report; Surgery

\section{Introduction}

PRMC was first described by Calo PG, et al. in 1924 [1]. PRMC is an extremely rare disease, and its biological behavior still lacks sufficient evidence-based medical evidence. The clinical manifestation of patients is an abdominal mass with paroxysmal pain in the mid-abdomen, and its symptoms are not specific and are often misdiagnosed by doctors, so attention needs to be paid. Interestingly, relevant literature reports that PRMC almost always occurs in female patients, and its pathogenesis is unclear [2]. In many discussions, whether sex differences are a key factor in the pathogenesis of PRMC is still unknown. This article reports a case of a young woman with a giant retroperitoneal mucinous cystadenoma successfully resected under laparoscopic surgery and reviews the literature.

\section{Case Presentation}

\section{Chief complaints}

A 24-year-old woman had intermittent left abdominal pain for 4 months.

\section{History of past illness}

The patient had no previous medical history.

\section{Imaging examinations}

Computed tomography (CT) showed an oval low-density shadow on the left paracolic sulcus, with clear edges, a size of $65.3 \mathrm{~mm} \times$ $55.4 \mathrm{~mm} \times 99 \mathrm{~mm}$, uniform internal density and a CT value of $4.6 \mathrm{Hu}$ (Figure 1). Because part of the small intestine was compressed by 
the tumor, the patient developed incomplete intestinal obstruction and intermittent abdominal pain. The performance of the patient's intestinal obstruction and abdominal pain was exacerbated, so we planned to use laparoscopic exploration to relieve tumor compression. To avoid damaging the blood vessels of important organs during the operation, we needed to know the blood supply of the tumor and its adhesion to adjacent tissues (Figure 2).

Under laparoscopy, we observed that the inner and outer walls of the tumor were smooth, and adhesion to the surrounding tissues was not tight (Figure 3). Because the phrenic nerve was stimulated when the top of the tumor was surgically stripped, the patient had respiratory depression during the operation.

\section{Pathological examination}

The pathology report showed that the retroperitoneal cyst was a large vesicle with a size of $11.5 \mathrm{~cm} \times 8.5 \mathrm{~cm} \times 3.5 \mathrm{~cm}$, and it contained clear liquid, had a smooth outer wall with a size of $0.1 \mathrm{~cm}-0.2 \mathrm{~cm}$ and had a small amount of adipose tissue attached to the local surface (Figure 4). The results of immune histochemical examination showed that part of the cyst had a single layer of cubic or flat glandular

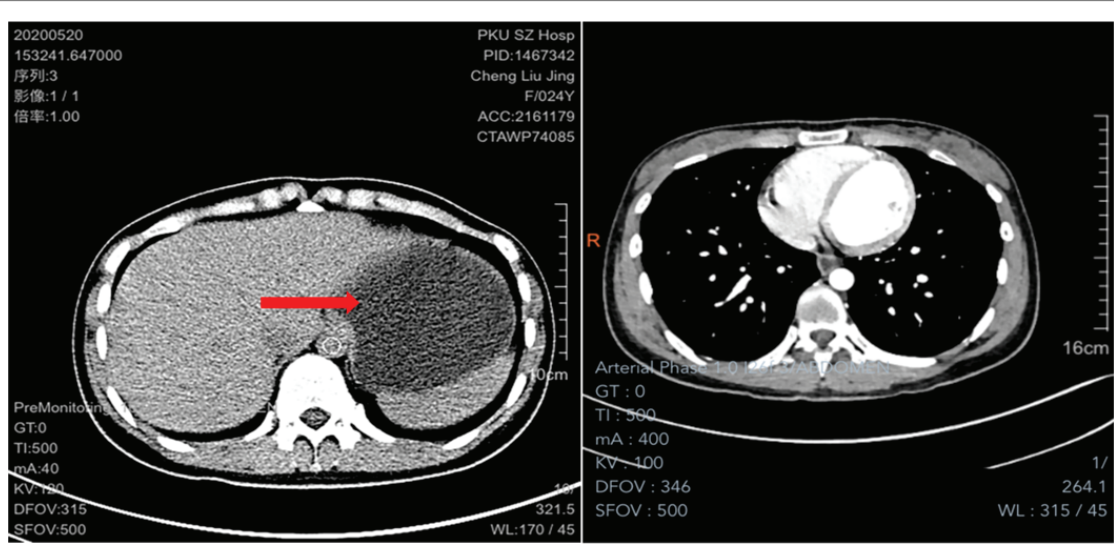

Figure 1: Computed Tomography (CT) showed the left retroperitoneal tumor, with a size of $65.3 \mathrm{~mm} \times 55.4 \mathrm{~mm} \times 99 \mathrm{~mm}$, clear border, single room, and cystic mass.

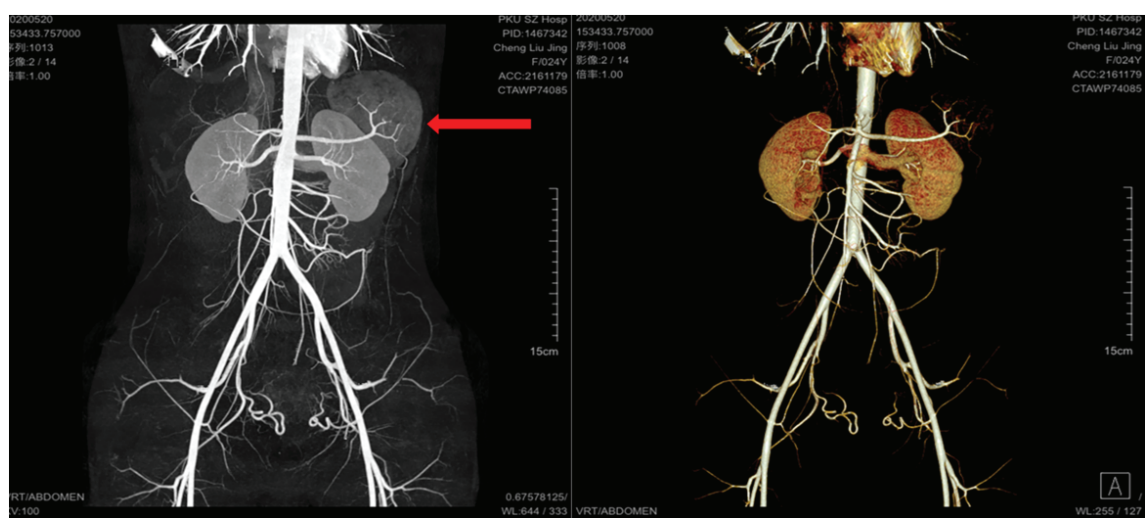

Figure 2: The vascular reconstruction image showed that there was less blood supply in the cyst and that it contained clearer fluid.

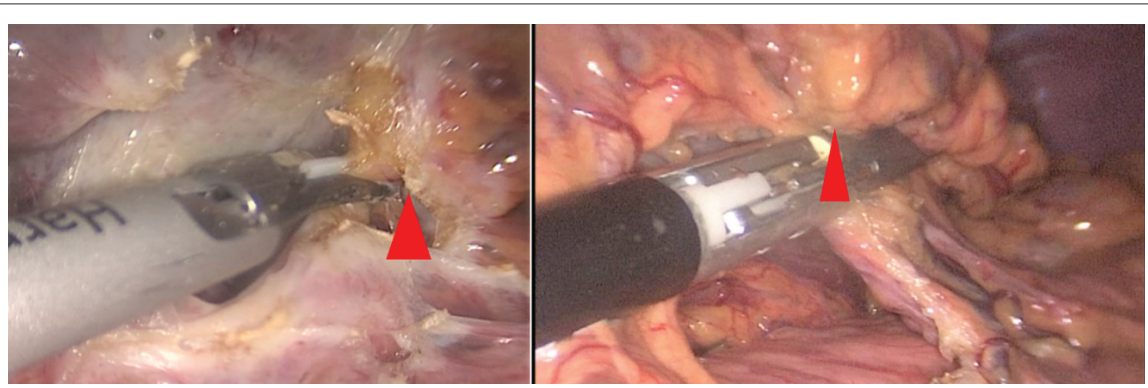

Figure 3: The intraoperative image showed the large, smooth outer wall of the posterior peritoneum on the left side, which did not adhere closely to the surrounding tissues, and A small amount of fat tissue can be seen on the surface of the mass and the surrounding area under laparoscopy. 
epithelium. Some mucous columnar epithelial cells were positive for CDK7, ER, AB (Alcian Blue) and PAS (Figure 5).

\section{Final Diagnosis}

Pathologists in Peking University-Hong Kong University of Science and Technology Medical Center Biocell Research Laboratory suspected that the tumor was a PRMC.

\section{Treatment}

After informing the patient and her families of the surgical plan and risks, we recommended expanding the scope of tumor resection or adjuvant treatment.

\section{Outcome and Follow-up}

The patient did not complain of obvious discomfort 1 week after the operation, and the symptoms of abdominal pain and intestinal obstruction disappeared. She refused further treatment but agreed to return to our hospital for review 3 months after the operation, and the patient's last abdominal CT examinations did not show any signs of recurrence or other complications.

\section{Discussion and Conclusion}

The early diagnosis and treatment of primary retroperitoneal mucinous cystadenoma present great challenges to surgical doctors, and Imaging examinations are difficult to diagnose and differentiate. We need to differentiate PRMCs from mesangial lymphatic cysts, cystic teratomas and retroperitoneal neurogenic tumors [3-5]. Laparoscopy is used frequently and has shown great clinical value in the treatment of PRMC, and we found that laparoscopic resection of retroperitoneal cystadenoma is a very good minimally invasive surgical method, and there are patients [6-9] with small incision, less trauma, better postoperative prognosis. There are several reports on

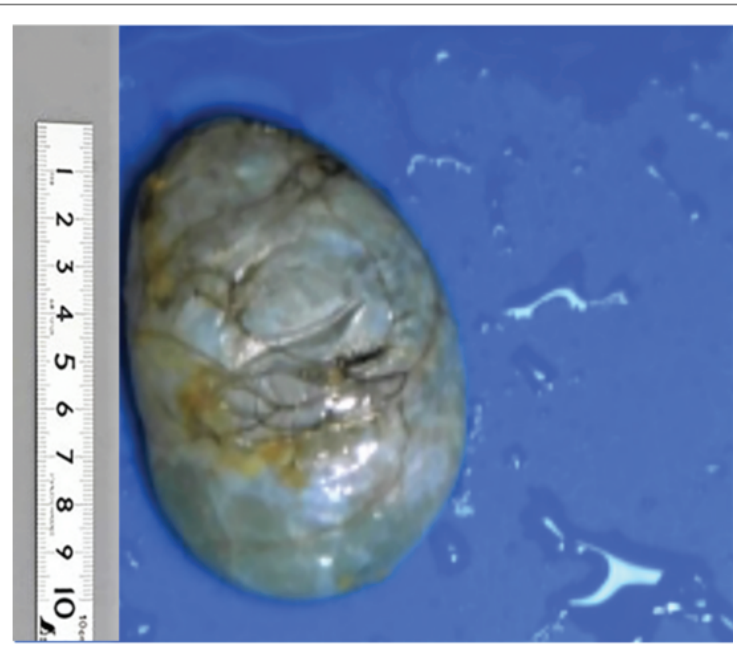

Figure 4: The excised specimens were found to be unilateral cysts, mostly fibrous cystic lesions, with little calcification on the cyst wall, smooth inner and outer walls, and clear and transparent liquid inside.

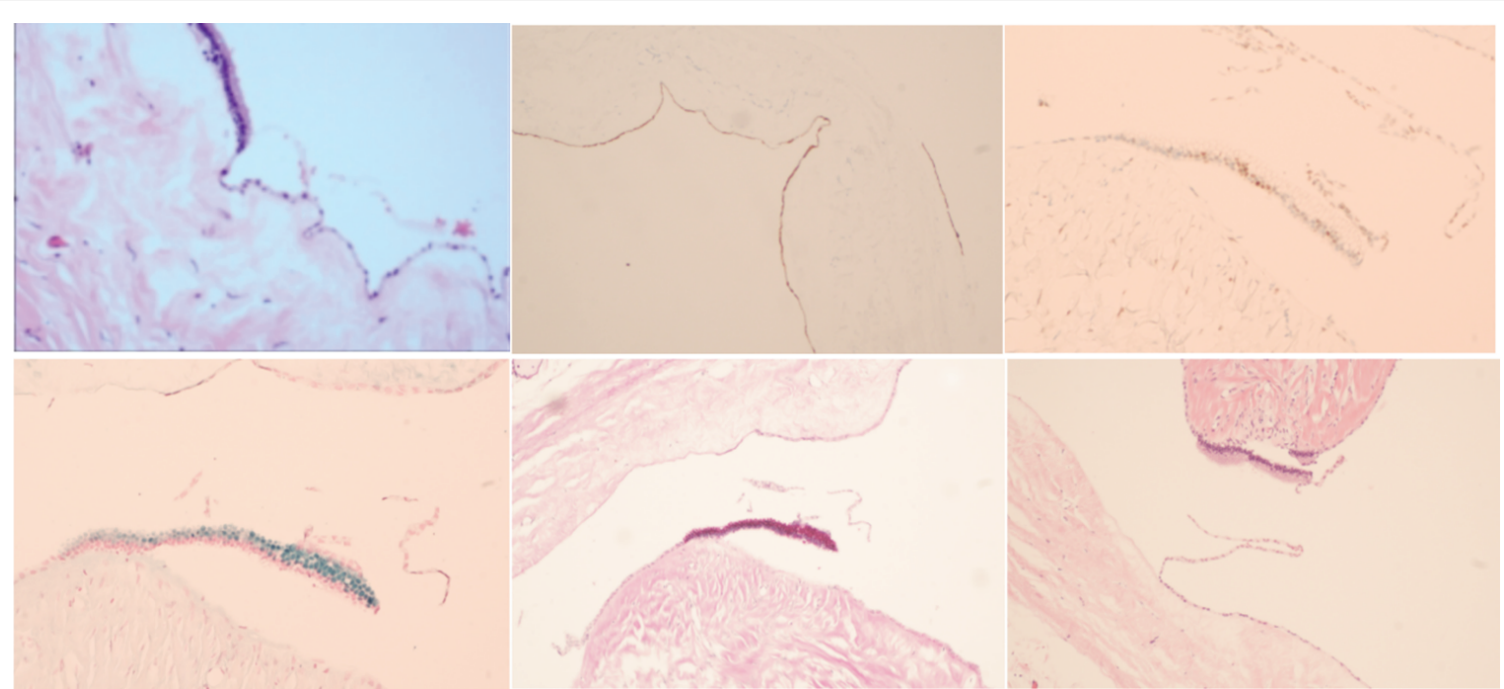

Figure 5: The tumor cyst wall is composed of single cuboidal and flat glandular epithelial cells. Immuno histochemical examination revealed CDK7 $(+), \operatorname{ER~(+),~AB~(Alcian~Blue)~(+)~and~PAS~(+).~}$ 
the use of laparoscopy for PRMC resection, but there are more reports on the transabdominal approach and less on the retroperitoneal approach [10]. In the open resection approach, and surgeons have a greater operating space, the intestine and peritoneal tissue need to be separated, and the operation time will be extended [11]. Although laparoscopy does not require separation of too much tissue and the greatly shortened operation time, but the disadvantage is that the operation space is only the retroperitoneal space, and the tumor cyst wall is easily broken when the tumor is removed, causing the contents of the cyst to disseminate into the peritoneal cavity [12]. Therefore, this type of posterior peritoneal surgery has a higher risk and higher surgical requirements for surgical doctors. However, regardless of which surgical method is used, the use of laparoscopy for PRMC resection is currently the most effective treatment $[13,14]$. In short, when patients with suspected PRMC lesions are identified and there are no related contraindications, laparoscopic abdominal mass resection is the first choice for the treatment of PRMC.

In our study, we reviewed 14 literatures on surgical treatment of PRMC, and summarized the clinical characteristics, pathological and imaging manifestations, potential malignant tendency of tumors, and surgical mode selection of PRMC (Table 1).

Our study reviewed the literature for nearly 20 years and found that cases of PRMC were mostly reported in women, but rarely in men. Feng JF, et al. [21], Shiau JP, et al. [22] and Thamboo TP, et al. [18] reported cases of male PRMC. Afzal Z, et al. [25] once counted 50 female patients with PRMC, most of them were young women and middle-aged women $(90 \% \pm 1 \%)$, and the age was mainly $(33.5 \pm 5.0)$. However, we found that male patients were mostly elderly, and the age was mainly $(62.0 \pm 2.0)$. We can't help but wonder if there is the difference of gender and age in the incidence of PRMC [15].

Hanhan HM, et al. [16] reported cases of PRMC in pregnant female, which is extremely rare. At present, no more than 10 cases have been reported in the world [3,17]. Hanhan HM, et al. also found that pregnant women of tumor size: $220 \mathrm{~mm} \times 130 \mathrm{~mm} \times 110 \mathrm{~mm}$, and they planned to perform laparoscopic surgery to remove the PRMC in order to minimize the harm of the pregnant woman. This minimally invasive surgical approach has obvious advantages in the treatment of cystadenomas [19-23].

With the development of medical equipment technology, more and more laparoscopy techniques are used in surgical operation. At present, laparoscopic resection is the main treatment in the surgical treatment of PRMC. However, Kanayama T, et al. [24] adopted Open surgery in consideration of the tumor size $\geq 250 \mathrm{~mm}$, and Thamboo TP, et al. [18] and Fujita N, et al. [27] changed the surgical method from laparoscopic surgery to open surgery due to the malignant transformation of the tumor in the PRMC patients.

\section{Author Contributions}

Yanwei Lai designed the research; Xiaoqiang Li performed the

Table 1: Cases of primary retroperitoneal mucinous cystadenoma reported in the literature [14-28].

\begin{tabular}{|c|c|c|c|c|c|c|c|}
\hline Study & $\begin{array}{l}\text { Years of } \\
\text { reports }\end{array}$ & Gender & Age & Area & Symptom & $\operatorname{Size}(\mathrm{mm})$ & Treatment \\
\hline Koyama R, et al. [15] & 2019 & Female & 39 & Japan & $\begin{array}{l}\text { Tension and pain in the left } \\
\text { flank }\end{array}$ & 20 & Laparotomy \\
\hline Pesapane F, et al. [16] & 2018 & Female & 52 & Italy & $\begin{array}{l}\text { Abdominal pain and a palpable } \\
\text { mass }\end{array}$ & $121 \times 81$ & Laparotomy \\
\hline Tokai H, et al. [14] & 2017 & Female & 29 & Japan & $\begin{array}{l}\text { Abdominal pain and a cystic } \\
\text { mass }\end{array}$ & $85 \times 80$ & Laparotomy \\
\hline Zanoni D, et al. [17] & 2015 & Female & $\mathrm{N} / \mathrm{A}$ & Italy & Abdominal mass & N/A & $\begin{array}{l}\text { Radiotherapy and } \\
\text { chemotherapy }\end{array}$ \\
\hline Dong A, et al. [18] & 2015 & Female & 52 & China & $\mathrm{N} / \mathrm{A}$ & $38 \times 34$ & $\mathrm{~N} / \mathrm{A}$ \\
\hline Hanlian HM, et al. [19] & 2014 & $\begin{array}{l}\text { Pregnant } \\
\text { Female }\end{array}$ & 37 & Turkey & Cystic mass & $220 \times 130 \times 110$ & Laparotomy \\
\hline Kurita T, et al. [20] & 2014 & Female & 30 & Japan & Abdominal tumor & $\mathrm{N} / \mathrm{A}$ & $\begin{array}{c}\text { Laparoscopic surgery and } \\
\text { chemotherapy }\end{array}$ \\
\hline Feng JF, et al. [21] & 2013 & Male & 63 & China & Clironic lower back pain & $40 \times 30 \times 40$ & Laparotomy \\
\hline Sliiau JP, et al. [22] & 2013 & Male & 59 & Taiwan & $\begin{array}{l}\text { A left retroperitoneal cystic } \\
\text { mass }\end{array}$ & $75 \times 30 \times 70$ & Laparotomy \\
\hline Demirel D, et al. [23] & 2013 & Female & 34 & Turkey & Retroperitoneal cystic mass & $140 \times 10 \times 80$ & Laparotomy \\
\hline Kanayama T, et al. [24] & 2012 & Female & 40 & Japan & $\begin{array}{c}\text { A progressive abdominal } \\
\text { distension }\end{array}$ & 250 & Open surgery \\
\hline Fiijita N, et al. [25] & 2012 & Male & 71 & Japan & Abdominal tumor & 100 & Open surgery \\
\hline Kasliima K, et al. [26] & 2008 & Female & 28 & Japan & Abdominal tumor & 170 & Laparotomy \\
\hline Thamboo TP, et al. [27] & 2006 & Male & 64 & Singapore & $\begin{array}{l}\text { A large retroperitoneal cystic } \\
\text { tumor }\end{array}$ & $240 \times 200 \times 160$ & Open surgery \\
\hline Carabias E, et al. [28] & 1995 & Female & 43 & Spain & $\begin{array}{l}\text { A palpable right-sided } \\
\text { abdominal mass }\end{array}$ & 150 & $\mathrm{~N} / \mathrm{A}$ \\
\hline
\end{tabular}

N/A: Not Applicable 
research; Jian Li contributed to pathologic diagnosis; Liusheng $\mathrm{Wu}$ wrote the paper.

\section{Conflict of Interest Statement}

The authors declare that they have no conflict of interest.

\section{Fund Project}

This work was supported by grants from the National Natural Science Foundation of China (81972829), the Science and Technology Innovation Committee of Shenzhen Municipality (Grant No. JCYJ20180228162607111, JCYJ20190809104601662), the Health and Family Planning Commission of Shenzhen Municipality Research Project (Grant No. SZBC2018018), China Scholarship Council (CSC, 201908440124).

\section{References}

1. Calo PG, Congiu A, Ferreli C, Nicolosi A, Tarquini A (1994) Primary Retroperitoneal Tumors. Our Experience. Minerva Chir 49: 43-49.

2. Danen C, Leschke T, Bassi D, Sharma R (2020) First Report of Retroperitoneal Mucinous Cystadenoma in a Patient with Hirsutism. Clin Med Res 18: 27-32.

3. Pesapane F, Renterghem SV, Patella F, De Visschere P, Villeirs G (2018) A Case Report and a Literature Review of Primary Retroperitoneal Mucinous Cystadenoma: The Importance of Imaging in Diagnosis and Management. Future Oncol 14: 2923-2931.

4. Koyama R, Maeda Y, Minagawa N, Shinohara T, Hamada T (2019) Laparoscopic Resection of a Primary Retroperitoneal Mucinous Cystadenoma. Case Rep Gastroenterol 13: 159-164.

5. Roma AA, Malpica A (2009) Primary Retroperitoneal Mucinous Tumors: A Clinicopathologic Study of 18 Cases. Am J Surg Pathol 33: 526-533.

6. Paraskevakou H, Orfanos S, Diamantis T, Konstantinidou A, Patsouris E (2014) Primary Retroperitoneal Mucinous Cystadenoma. A Rare Case with Two Cysts and Review of the Literature. Hippokratia 18: 278-281.

7. Nam YJ, Tae Kim N, Kim KH, Gu MG, Lee JY (2014) A Case of Primary Retroperitoneal Mucinous Cystadenoma Arising from the Retropancreatic Area. Korean J Gastroenterol 63: 187-190.

8. Vicario FJ, Estalella L, Hermoso J, Díaz F, Gris P (2016) Primary Retroperitoneal Mucinous Cistoadenoma. An Uncommon Tumour in a Young Woman. Cir Esp 94: 243-245.

9. Del Gobbo A, Bimbatti M, Ferrero S (2010) A Case Report of Mesenteric Mucinous Cystoadenoma with Review of the Literature. BMC Gastroenterol 10: 105.

10. Prabhuraj AR, Basu A, Sistla SC, Jagdish S, Jayanthi S (2008) Primary Retroperitoneal Mucinous Cystadenoma in a Man. Am J Clin Oncol 31: 519-520.

11. Miettinen MM, Antonescu CR, Fletcher CDM, Kim A, Lazar AJ, et al. (2017) Histopathologic Evaluation of Atypical Neurofibromatous Tumors and their Transformation into Malignant Peripheral Nerve Sheath Tumor in Patients with Neurofibromatosis 1-a Consensus Overview. 67: 1-10.

12. Lax SF (2019) Pitfalls and Common Problems in the Differential Diagnosis of Epithelial Ovarian Tumors. Pathologe 40: 46-60.
13. Afriat R, Mechet I, Rachedi N, Michenet P, Bardaxoglou E, et al. (1995) Primary Retroperitoneal Mucinous Cystadenoma: A Case Treated by Celioscopic Surgery. J Chir (Paris) 132: 67-69.

14. Tokai H, Nagata $Y$, Taniguchi K, Matsumura N, Kitasato A, et al. (2017) The Long-Term Survival in Primary Retroperitoneal Mucinous Cystadenocarcinoma: A Case Report. Surg Case Rep 3: 117.

15. Koyama R, Maeda Y, Minagawa N, Shinohara T, Hamada T (2019) A Rare Case of Primary Retroperitoneal Cystadenoma with a Mural Nodule and High Serum CA19-9 Level. Am J Case Rep 20: 833-837.

16. Hanhan HM, Gungorduk K, Ozdemir IA, Gokcu M, Sanci M, et al. (2014) Primary Retroperitoneal Mucinous Cystadenocarcinoma During Pregnancy. J Obstet Gynaecol 34: 535-538.

17. Zanoni D, Sikokis A, Bersanelli M, Gnetti L, Buti S (2015) Retroperitoneal Cystoadenocarcinoma: a Case Report with a Literature Review. Acta Biomed 86: 97-105.

18. Thamboo TP, Sim R, Tan SY, Yap YM (2006) Primary Retroperitoneal Mucinous Cystadenocarcinoma in a Male Patient. J Clin Pathol 59: 655-657.

19. Carabias E, Muñoz HG, Dihmes FP, Pino MAL, Ballestín C (1995) Primary Mucinous Cystadenocarcinoma of the Retroperitoneum. Report of a Case and Literature Review. Virchows Arch 426: 641-645.

20. Demirel D, Gun I, Kucukodaci Z, Balta AZ, Ramzy I (2013) Primary Retroperitoneal Mucinous Cystadenoma with a Sarcoma-Like Mural Nodule: an Immunohistochemical Study with Histogenetic Considerations and Literature Review. Int J Gynecol Pathol 32: 1525.

21. Feng JF, Liu H, Chen DB (2013) Primary Retroperitoneal Mucinous Cystadenocarcinoma in a Male Patient: A Rare Case Report. Hippokratia 17: 271-273.

22. Shiau JP, Wu CT, Chin CC, Chuang CK (2013) Long-term survival After Hand-Assisted Laparoscopic Approach of Primary Retroperitoneal Mucinous Cystadenocarcinoma in Male: Case Report and Review of Literature. Eur Surg 45: 106-109.

23. Dong A, Zhai Z, Wang Y, Zuo C (2015) MRI, Enhanced CT, and FDG $\mathrm{PET} / \mathrm{CT}$ in Primary Retroperitoneal Mucinous Cystadenocarcinoma. Clin Nucl Med 40: 50-53.

24. Kanayama T, Yoshino K, Enomoto T, Ohashi H, Fujita M, et al. (2012) Primary Retroperitoneal Mucinous Cystadenocarcinoma with Mural Nodules: A Case Report and Literature Review. Int J Clin Oncol 17: 407-411.

25. Afzal Z, Stupalkowska W, Mahler-Araujo MB, Bowden D, Davies RJ (2020) A case of successful surgical management of primary retroperitoneal mucinous cystadenoma. J Surg Case Rep.

26. Kurita T, Nakajima K, Koi C, Matsuura Y, Hachisuga T (2014) Management of a Primary Retroperitoneal Mucinous Cystadenocarcinoma: Case Report. Eur J Gynaecol Oncol 35: 163166.

27. Fujita N, Nishie A, Asayama Y, Kiyoshima K, Kubo Y, et al. (2012) A Male Case of Primary Retroperitoneal Mucinous Cystadenoma: A Diagnostic Dilemma. Japane J Radiol 30: 594-597.

28. Kashima K, Yahata T, Fujita K, Tanaka K (2008) Primary Retroperitoneal Mucinous Cystadenocarcinoma Associated with Pregnancy. Int J Gynecol Canc 18. 